\title{
FORMATION AND DEVELOPMENT OF SKILLS FOR PROACTIVE DRIVING LICENCE (ACCORDING TO INSTRUCTORS)
}

\author{
Margarita Pehlivanova, Zlatoeli Ducheva \\ Faculty of Technics and Technologies of Yambol, Trakia University of Stara Zagora \\ 38 "Graf Ignatiev" str., Yambol 8600, Bulgaria \\ E-mail: margopehlivanova@abv.bg, zl.ducheva@abv.bg
}

\begin{abstract}
In the system "man - environment - motor vehicle", the driver and his training are the main factors to overcome the negative trends of increasing the number of victims and injured in traffic accidents. The proactivity of the driver is associated with high levels of global purpose of drivers' training - with the strategic level, which includes personal characteristics, ambitions, values and choices of behaviour models. In the presented report we analyze the results of a survey conducted during the courses of periodic training of instructors from around the country in which were switched on the question for ranking the elements of the proactive driving according to the experience and perception of the trainers. Were analyzed the results obtained from 403 respondents from different size and geography settlements. We assume that all eleven components that we included and their arrangement in order of importance reflect the mind-set and attitudes of learners to proactive driving and correct actions which ensure personal and safety of other participants are manifestations of tolerance. We can conclude that at the forefront of arranging of the components of proactive driving, the respondents emphasize on those, that increase the traffic safety (manoeuvre planning, forecasting), but underestimate the knowledge of prior knowledge of the risk factors that increases the probability of road accidents.
\end{abstract}

Keywords: proactivity, components of to proactive driving, skills for proactive driving.

\section{INTRODUCTION}

In the system "man - environment - motor vehicle ", the driver and his training are the main factors to overcome the negative trends of increasing the number of victims and injured in traffic accidents. Based on scientific research and analysis of the reasons for road accidents in the European countries was developed a global objective for the preparation of the drivers and was added behavioural level, which is related to abstract-logical thinking with the attitudes and values of the individual and the community for defensive, proactive driving.

Researchers and trainers of drivers point out that the preparation of a more responsible and confident in their competence drivers does not refer to the formation of skills and competencies for racing drivers, but also to develop skills for proactive driving. In some countries are offered courses not only for novice drivers, but also for those who have a long experience since the statistics show that participants in road transport accidents are also experienced drivers. Therefore, much attention is paid to the understanding of the drivers of proactive behaviour.

\section{THEORETICAL TREATMENTS}

The concept "proactive" means: an active and enterprising and also prescient, provident person. The definition which St. Covey gives is associated with high levels of global purpose of drivers' training - with the strategic level, which includes personal characteristics, ambitions, values and choices of behaviour models. The model of behaviour that we choose is connected and determined mainly by the choices and decisions we make and the 


\section{ART'TL $Y^{2}$}

Ipplied Resseirlohes in Technics, Technologies and Bductation

Journal of the Faculty of Technics and Technologies, Trakia University https://sites.google.com/a/trakia-uni.bg/artte/

responsibility that we take, and the consequences of our decisions. $[1,2,3,4,7]$ The competence related to the proactive approach reflects the natural interest of man to things, events and connections between phenomena in the world, the ability proactively to seek and discover new opportunities to do different activities, but also to change the environmental conditions, rules and regulations and to transform the surrounding reality.

The proactivity of the person connects to skills to anticipate and overtake an event with effective action, which is especially important for conditions of intensive traffic. We can accept that the principles of proactivity in the field of management and marketing can be valid and the training of drivers in the forming and developing of their skills and competencies. Contemporary trends are educational objectives to be placed together with the trainees, as they are associated with effective training and increasing the degree of autonomy and confidence of prospective drivers also in the basic training. It is important at the basic training prospective drivers to be motivated and understand that the goal of the training is important for them and that is not associated only passing of the exams and obtaining a certificate, but also with health and life as the highest values, continuous development of competencies to drive and the formation of transport culture. The components of the goal, related to the security, the safer driving and experience that brings satisfaction to the prospective driver, compliance of the current regulations should be adopted by the learner, and be compatible with their individual needs and interests.

For the development of skills for a proactive behaviour while driving the instructor needs to express clear goals that set, but also to enable the learner to determine his own purposes. This is a process that continues throughout the course, as closer targets that are associated with successful completion of the theoretical and practical exams are considered easier by the candidates. The most important components of goal related to the motives, attitudes, values and transport culture are more common and more difficult for expression and transformation in personal goals of the learners so that they can pursue them in the period of independent driving. Here we would like to emphasize the importance of the development of independent critical thinking among drivers so that based on statistics for road accidents trainees would be able to determine their own priorities in independent practice, they can find timely problems and weaknesses in the levels of development their own abilities and competencies. Of particular importance is the early detection of more dangers when driving in an intensive traffic on unknown routes and skills for risk analysis and taking preventive measures to prevent accidents, instead of overcoming the consequences of accidents. In order to stimulate the development of criticality, increase self-dependence and confidence of candidate driver, the instructor must not only set out its rules and forbiddings, and to seek the active participation of the trainees, while interaction give a joint response to the causal relations between various actions and behaviours of drivers to answer the question "Why should I do/act this way?".

We consider the defence driving as a complex skill to anticipate problems and conflicts before they happen, i.e. the possibility the drivers to be proactive while driving rather than passive observers. With a particular force on the training as proactive drivers we can point to part of the definition of Stephen Covey. The author regarded proactivity not only as an initiative but as a responsibility for our own lives and our behaviour as a function of our decisions, actions and behaviour. Once again the results from research of other scientists and our studies confirm that emotional intelligence is particularly important for the models of behaviour while driving. We accept the opinion of Covey and we came to the conclusion that behaviours of Drivers isn't determined by the conditions at the moment, but rather by their decisions, control and subjugation of the feelings on the hierarchy of the values and taking a personal responsibility for the consequences.

In most of the countries in training of drivers talk about defensive or protective driving, using it as synonymous with proactive driving. It is seen as an accepted standard that ensures

\section{IRTIIE Vol. 4, No. 3, 2016 ISSN 1314-8788 (print), ISSN 1314-8796 (online), doi: 10.15547/artte.2016.03.011}


traffic safety, saves lives and saves money and time. Proactive approach means to engage outside the normal duties, to possess the ability to distinguish between emerging new opportunities to seek new alternatives and solutions and be able to overcome the difficulties. Driving as a very complex activity that requires the drivers to have the ability for monitoring of road transportation situations, to monitor arising of rapid changes in the traffic to overcome alone the difficulties, to react to developments and to be able to take alternative solutions. When driving, the proactive driver foresees the consequences and to think not only about themselves but also for the other road users.

Proactive drivers must have the ability to seek and make its own decision to look for alternative solutions to complex non-standard situations to detect various changes and opportunities in the road traffic. If take into consideration the proactive approach in preparing of drivers of motor vehicles, it will improve the effectiveness of the learning process and traffic safety. By focusing efforts on the proactive driving will improve the safety in driving, but also road environment will be safer for all road users. [1]

The personality of proactive driver of the vehicle is obeyed to impulsive reactions and their own values. Drivers who are reactive are often dependent on their own feelings, the pressure of the passengers in the vehicle, the behaviour of other road users, the conditions of the road environment. A proactive drivers also have feelings, but they are emotionally intelligent and obey behaviour of personality recognized and accepted values, i. e. on them impact an external factors (physical, social, psychological), but their choice of mode of action, and behaviour model is based on important values. Proactive drivers show initiative and Selfinitiative, they endeavour to guide their actions consciously, provide consequences and take responsibility for them. Proactive drivers have reached high levels of acquiring knowledge and skills, they can identify and solve problems by observing the principles and rules of traffic safety and be responsible drivers. It is very important in the complex conditions of intense traffic, the behaviour of proactive drivers to be not affected by social conditions of the environment and by the behaviour of the other road users.

When the instructor determines to which type of drivers refers the learner, first of all, the focus of proactive candidate-drivers should be on the circles of influence, which can affect. They should direct their energy to what falls under their influence and their energy in order to be positive and to increase the impact on the depended terms. The characteristic of reactive people we can compare with that of reactivity and aggressive drivers who seek reasons for their failure or road accidents weaknesses in driving the other drivers in the external environment and circumstances which cannot be directly affected. Usually this manifests itself in the behaviour in the form of complaints, accusations against the other participants and supervisory authorities in presenting themselves as victims.

Some authors point as an indicator to determine proactivity and reactivity in people's behaviour, their speech. This indicator can connect with the interactive personality-oriented training of drivers. Therefore on methodological guidance paying attention to the placing "open" questions, developing the skills to identify and formulate problems, to seek options and methods of solution to make responsible choices and to manage their feelings and interactions with other road users. [8]

\section{DESIGN OF THE STUDY}

In the presented report we analyze the results of a survey conducted during the courses of periodic training of instructors from around the country in which were switched on the question for ranking the elements of the proactive driving according to the experience and perception of the trainers. The survey was conducted through questionnaires as a part of the questions require answers for ranking according to their importance and according to personal professional and social experience of the instructors. Were analyzed the results

IRTIIE Vol. 4, No. 3, 2016 ISSN 1314-8788 (print), ISSN 1314-8796 (online), doi: 10.15547/artte.2016.03.011 


\section{ARTTIE $Y$}

Ipplied Resseirl'hes in Teednicis, Technologies and Eductation

Journal of the Faculty of Technics and Technologies, Trakia University https://sites.google.com/a/trakia-uni.bg/artte/

obtained from 403 respondents from different size and geography settlements. Were included data from the survey of Sofia, Varna, Veliko Tarnovo, Blagoevgrad, Yambol, Kyustendil, Lovech and Dupnitsa. The results are processed as we searched the influence of age and professional experience as instructors for the training of drivers for determining the significance of the main components of proactive driving. The data on demographic indicators were converted into results, the respondents were divided into age groups according to the classification developed by the researchers of the career Levinson (Levinson et al. 1986), Arnold and Feldman (Arnold and Feldman, 1986) and Shane (Schein, 1978) and summarized by D. Iskrev: pre-career - 15-22 years, early career - trial 22-30 years, early career - setting 30-38 years, middle career - transition 38-45 years, middle career - growth 45-55 years, later career - keeping 5562 years, late career - discontinuance 62-70 years.

The majority of respondents were in the age of the average career - growth, followed by instructors - later career - maintenance, late career - discontinuance from active professional activity. There is a trend that instructors remain active acting and over 62 years - they are the third largest group of the investigated. It is worrying the fact that a minimum number from the graduated young people with professional qualification "instructor" are at the stage of early career - "trial" and "establishment" and they are included in driver's training. The first two age groups (22-30 years and the $30-38$ years) are only $11 \%$. If we assume that the professional and social experiences are important for the enhancement of competence and the increase the effectiveness of training, the positive is the fact that the group of representatives of the average career is prevalent. The research tool contains basic conceptually displayed skills of a proactive/ defensive driving, and the respondents had to rank on the first place the most important skill according to their opinion and on 11-th place the least important. The whole dataset is processed by software STATISTICA 7, as calculated the mode, and the median central tendency of each of the 11 assertions and was made frequency analysis of the places that received each of them.

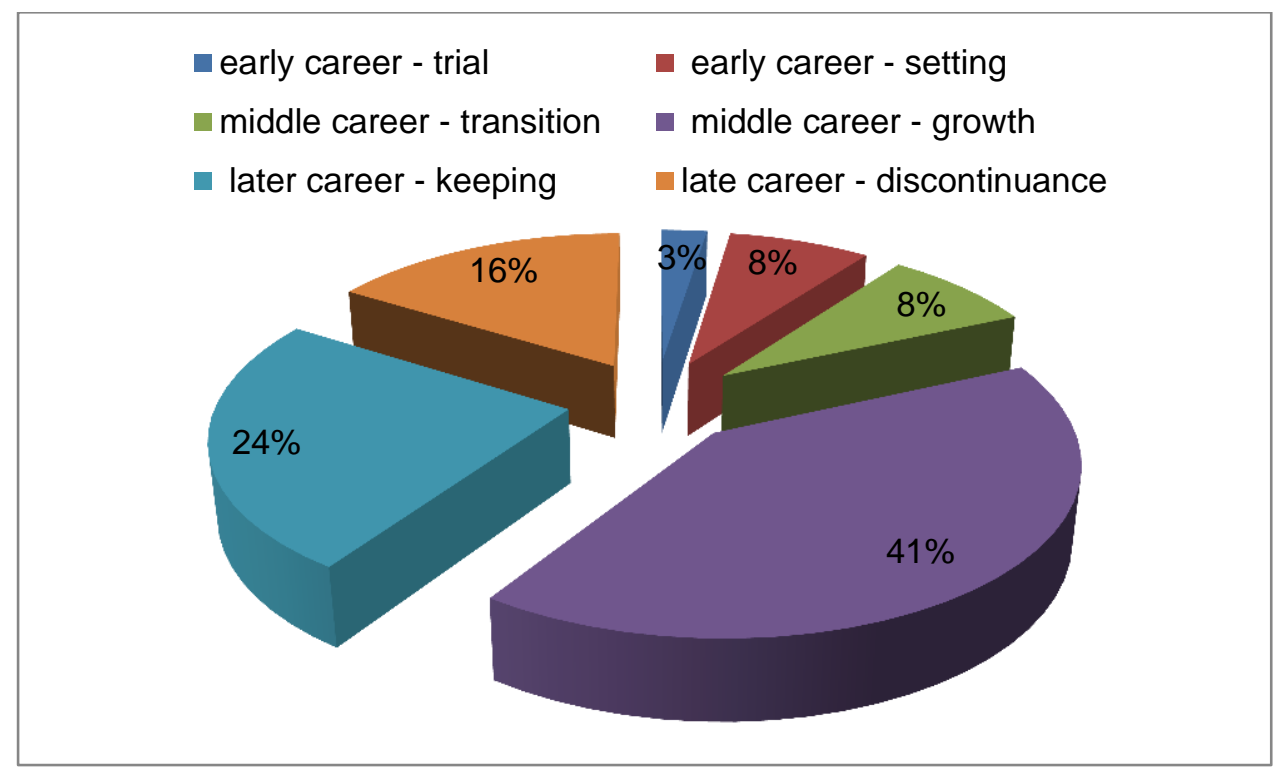

Figure 1. Distribution of the instructors according to age groups

In the analysis of results we look for connection and we will report the impact of the professional experience in the ranking of the main components of proactive driving. The surveyed Instructors were divided into 4 groups, the first group has a length of service up to

IRTIIE Vol. 4, No. 3, 2016 ISSN 1314-8788 (print), ISSN 1314-8796 (online), doi: 10.15547/artte.2016.03.011 


\section{ARTTIE $Y$}

Ipplied Researleches in Technics, Technologies and Bductition

Journal of the Faculty of Technics and Technologies, Trakia University https://sites.google.com/a/trakia-uni.bg/artte/

five years and the next were by increments of ten years and over 25 years. For the first group, we are guided from the theoretical formulation that the first five years are regarded as entry into the profession and initial adjustment to the organization and activities. In the other groups still practice the adjustment process and improve the professional competencies that are associated with a change in the understanding and teaching technology training in proactive driving.

The data analysis of the studied 403 respondents shows that regardless of age, internship and the settlement, the surveyed have ranked with the forward positions the skill to distribute of attention during driving. Approximately with equal rank the surveyed have indicated the skills to carry out maximum control over the car, the ability to see deep forward in traffic and making the right decisions. Next in the ranking is the complicated skill to predict the behaviour of other road users and detect potential threats or hazards. From the analysis of the results we can summarize that in the process of the training the instructors emphasize on the further development of attention and psychomotor performance, which is the basis of the safe driving. In addition, they understand the importance and role of higher levels of perception, analysis and summarizing of a traffic situations, early detection of the potential hazards and the role of the peripheral visual field for the safe driving. The respondents understand the importance of preventive activities during the preparation of drivers concerning knowledge of risk factors. It is not accidental that in many European countries and in projects related to driver training in the theoretical training and examination are included statistics on the most common accidents and the factors that lead to them.

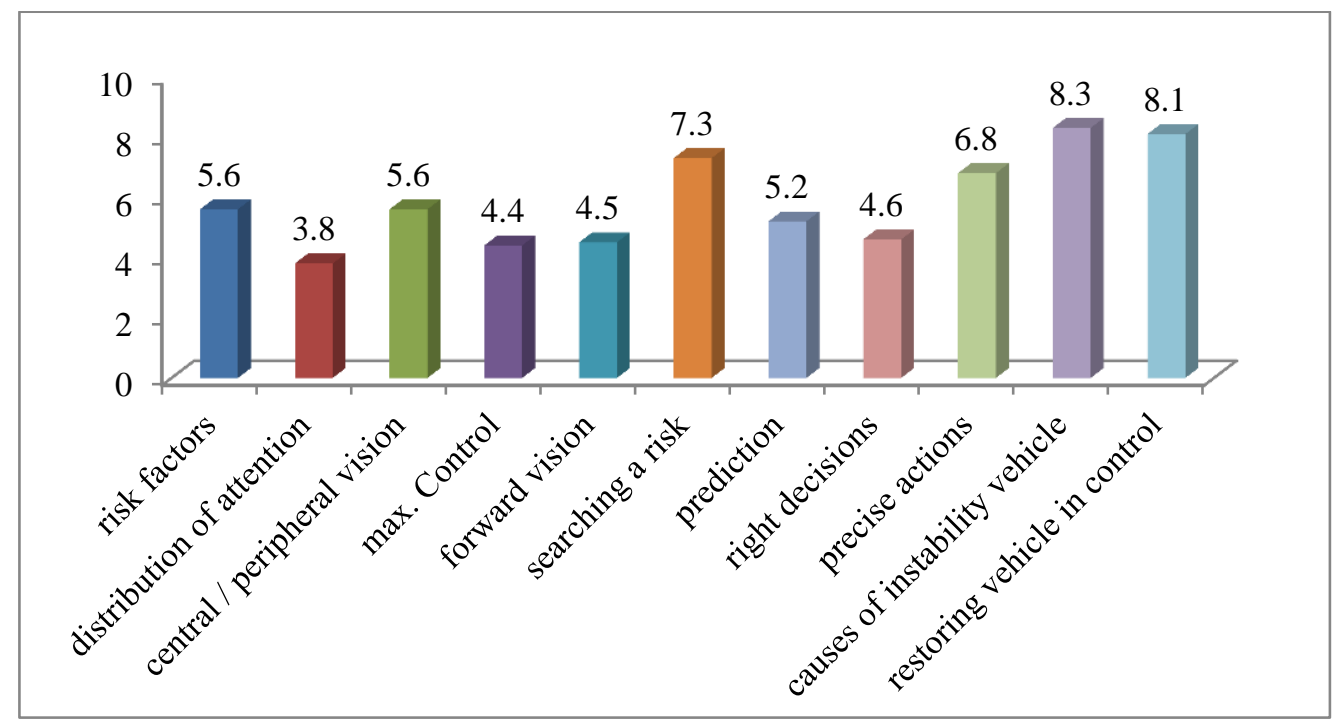

Figure 2. Ranking of the components of proactive driving (according to all surveyed)

At last two positions in the ranking are: detecting the causes of situations that lead to the loss of stability of the car and the knowledge, skills and experience for proper action on recovery control of the vehicle. These data we can explain because of the majority candidate drivers from various categories are included in the courses of basic training mainly in spring, summer and autumn in good weather conditions, visibility and mostly dry roads. The highcommand skills to manage and control the vehicle in a situation of aquaplaning, icy and slippery road segment usually are acquired in the first months of their individual driving.

The respondents who are on the stage middle career - transition believe that as a guiding element is the maximum control over the vehicle, followed by the ability to make the right decisions that skill show little difference from the predicting the behaviour of other road

IRTIIE Vol. 4, No. 3, 2016 ISSN 1314-8788 (print), ISSN 1314-8796 (online), doi: 10.15547/artte.2016.03.011 


\section{ART'TE $Y$}

Ipplied Resseirl ches in Technics, Technologies and Bductation

Journal of the Faculty of Technics and Technologies, Trakia University https://sites.google.com/a/trakia-uni.bg/artte/

users. The surveyed instructors in the age group 45-55 years (middle career - growth), as well as in the aggregated data have ranked on the first place distribution for the attention, followed by the ability to see deep forward in traffic, followed with little difference from the complex skills to take properly solutions in the dynamic and complex situations. In the next age group (55-62 years) in a manner of arrangement referred skill to distribute of attention, maximum control over the car, the ability to take the right decisions and deep vision forward in traffic.

The results from the survey of the instructors who are in the age of late career - withdrawal in ranking the skill to distribute of attention does not differ from general data in second place are placed, the ability to implement maximum control over the car, on the third - the ability to taking the right decisions and with a small difference the ability to look deep forward in the traffic flow.

In summary we can say that the role for the attention is particularly significant in driving. In the heavy traffic during the training and in the initial period from autonomous driving on the driver influencing various irritant. The incoming from the road transport environment stimuli differ by strength and duration of the impact on the senses and the driver can not react to all of them. Therefore the attention while driving is an extremely important factor because it determines the orientation of the psychological activity on the most significant impact from the surrounding environment or the traffic situation.

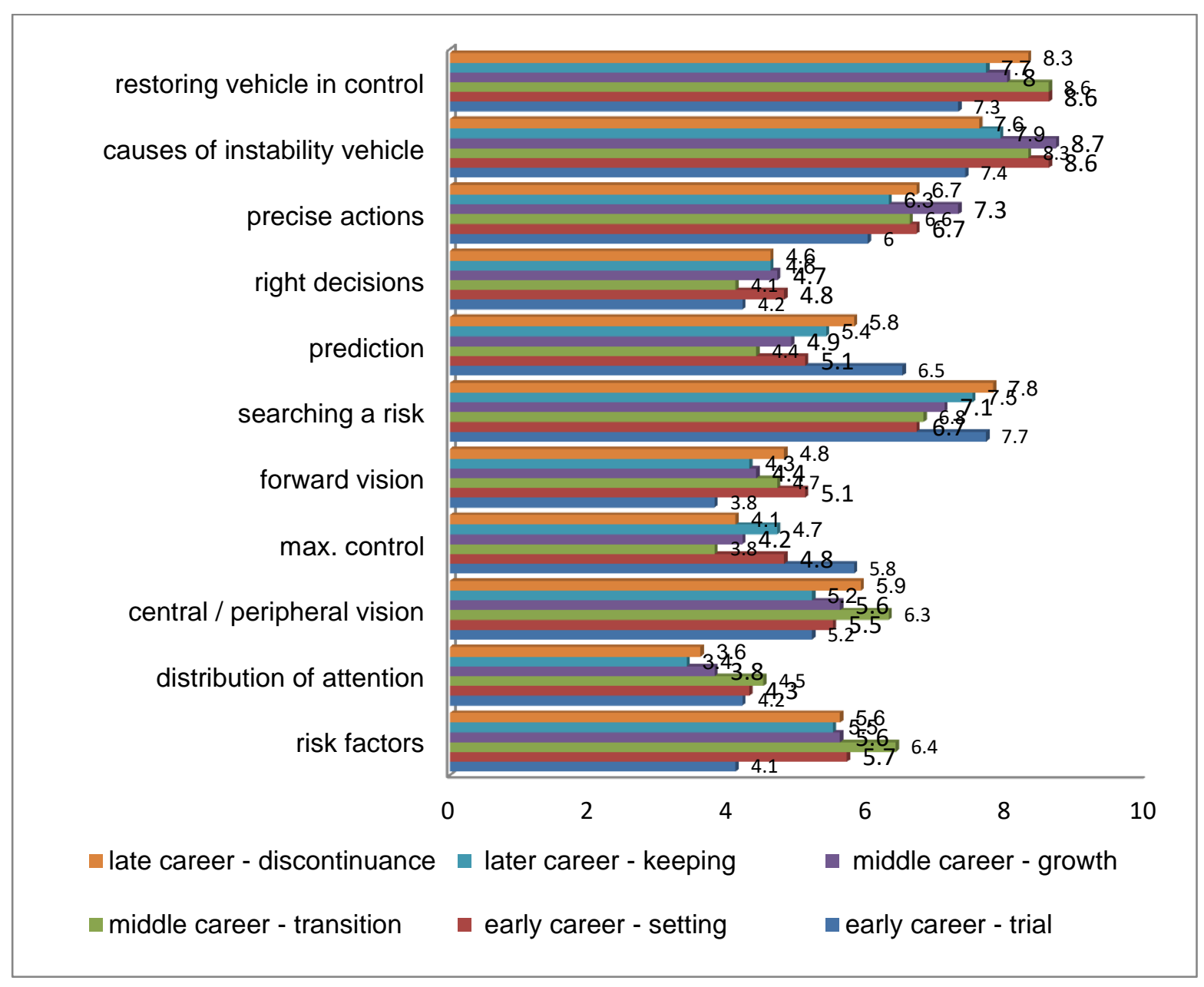

IRTIIE Vol. 4, No. 3, 2016 ISSN 1314-8788 (print), ISSN 1314-8796 (online), doi: 10.15547/artte.2016.03.011 


\section{ARTTLY $Y$}

Ipplied Resseirl'hes in Teednicis, Technologies and Eductation

Journal of the Faculty of Technics and Technologies, Trakia University https://sites.google.com/a/trakia-uni.bg/artte/

Figure 3. Ranking of the components of proactive driving (according to the age of the surveyed)

A positive fact is that representatives from all groups of respondents have put at the forefront the role for the attention and especially its distribution as one of its major features. Driving a car in modern conditions is a very complex activity and the Profession of the drivers' ranks as stressful after that of air traffic controllers and surgeons. While driving, drivers have to perceive many varied information from different objects and phenomena that influence with a different duration and strength. Also drivers done simultaneously several actions and operations (monitor the condition of traffic, carry out actions with the controls of the car, not only observe, but also need to anticipate the actions of other road users, etc.). In the analysis does not undermine the role of other basic features the attention - volume and switching that are important when driving. In an intensive traffic, drivers have to cover several objects simultaneously in dynamics for a short period of time, but they must also be able to redirect their attention within 2-3 seconds to watch in the rearview mirror in order not to miss the manoeuvre of another vehicle that could be a prerequisite for a conflict situation.

When processing the received data according to the professional experience of respondents, grouped in 4 groups, on first rank is the distribution of the attention among the representatives of the third group (16-25 years' experience), but with very similar average comes the ability to see deep ahead in the traffic, according to instructors who entering in the profession. The respondents from third, fourth and second group have indicated to the next position the role and importance of the attention and its features distribution as a leading, and the mean is very close for the representatives of the third and fourth group.

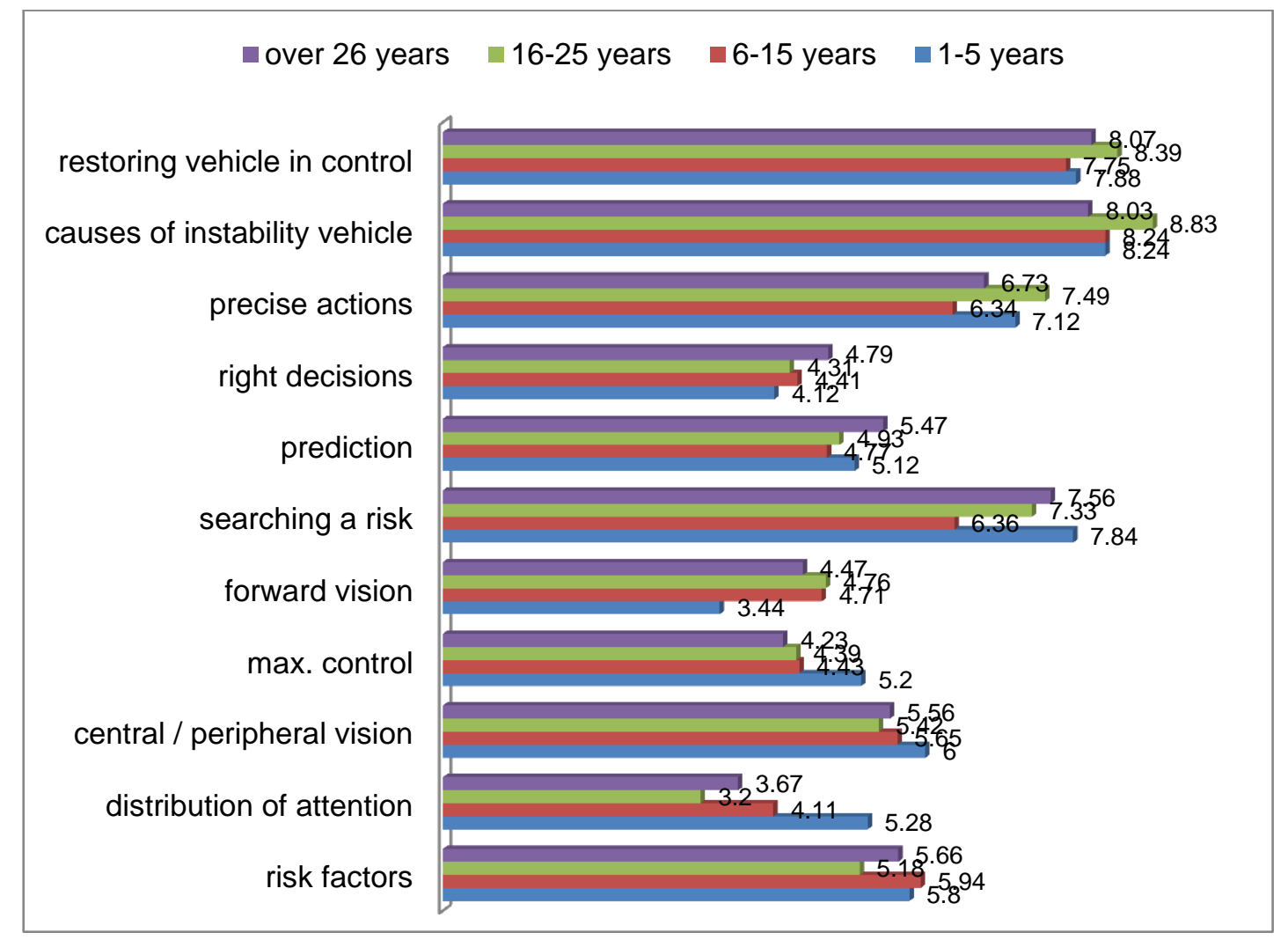

Figure 4. Ranking of the components of proactive driving (according to the professional experience)

IRTIIE Vol. 4, No. 3, 2016 ISSN 1314-8788 (print), ISSN 1314-8796 (online), doi: 10.15547/artte.2016.03.011 


\section{IRTTL $<>$}

Ipplied Resseirl ches in Technics, Technologies and Eductition

Journal of the Faculty of Technics and Technologies, Trakia University https://sites.google.com/a/trakia-uni.bg/artte/

The importance of taking the right decisions, based on observation and perception, and the skills for the distribution and switching of the attention, and to predict the behaviour of the other road users, gives a second place to this skill according to the respondents from the first and third group. Regardless of teaching experience, with similar values as the main component of proactive / defensive driving is ranked the ability to carry out maximum control over the car by the representatives of the fourth, third and second group.

It is noteworthy that despite the professional practice and accumulated experience all respondents, they do not pay attention to the ability to actively search for potential risk situations and dangers, which is connected with analytical and logical thinking and grading on the level of significance of certain components from the road transport situation. Analogously all respondents do not consider that the good prior knowledge of risk factors is an important element of proactive driving. In some European countries in conducting of the theoretical examination of drivers of various categories it is necessarily to include an elements of statistical data on the reasons causing accidents in the related state. This assumes that knowing of the factors that adversely affect to the driving and causes that lead most frequently to accidents have preventive matter of traffic safety. High values of central tendency shows that the ability to take correct action to ensure personal and that of other road users safety is not enough appreciated by all groups of instructors. Perhaps they accept a priori that the formation of sensomotoric and psychomotor skills and habits started at the beginning of basic training and that without them we cannot talk about the formation of more complex skills and competencies. Regardless of the professional experience is confirmed the overall finding to all respondents that the final positions in the ranking are placed the skills to detect the reasons that cause the loss of stability of the car and the knowledge, skills and experience of correct actions return the vehicle under control.

In recent years, many companies that prepare drivers advertise the courses of proactive driving by incorporating different components. In one of the proposals the main components of proactive driving are grouped into three groups: knowledge, skills and attitudes. As skills they have indicated: full control of the vehicle, timely identification of threats and concentration on tasks when driving in specific situations. These components are included in our questionnaire, but the respondents pay attention primarily on the first component. We haven't include the component for concentration, but rather for distribution and switching of attention, as we think they are very important because of the high dynamics of the contemporary traffic. Another component of proactively driving of motor vehicles are knowledge related to understanding of traffic rules and technical capabilities of motor vehicles as standard in the curriculum provided before transition to practical training for driving necessarily learned the first 7 themes for safety of the traffic and drive the vehicle. Seemed to underestimated the awareness and consideration of some technical aspects of active safety systems in modern vehicles, such as ABS, ESP, etc. knowledge of which and skilful use by drivers increases safety of the movement.

We assume that all eleven components that We included and their arrangement in order of importance reflect the mind-set and attitudes of learners to proactive driving and correct actions which ensure personal and safety of other participants are manifestations of tolerance. In basic training of drivers, the instructors must motivate the candidate-drivers to reflect on their own actions and behaviour during the practical training, and to be able to develop a higher degree of autonomy and self-criticism to his own model of behaviour. The individual form of practical training is requirement to comply with individual characteristics, placing the accent on defensive and proactive model of driving. 


\section{CONCLUSIONS}

From the analysis of various literature sources, best practices developed through various projects and from our research we can summarize:

1. The concept of proactive driving is associated with multiphasic models for training of drivers. In a proactive driving the focus is on initiative, a higher degree of autonomy and responsibility of drivers while driving.

2. The proactive behaviour while driving includes components from all levels of the global goal (GDE) for training drivers and pedagogical taxonomy of Bloom, highlighting the leading role of higher levels.

3. The respondents evaluate the importance of procedural knowledge, and connect it with the ability for maximum control over the car in movement, forming of specific skills, algorithms and techniques by following relevant procedures.

4. We must point out that instructors doesn't evaluated and ranked in order of importance the ability to control the vehicle in situations of loss of control and especially knowledge, skills and specific techniques for restoring stability of the car.

5. We can conclude that at the forefront of arranging of the components of proactive driving, the respondents emphasize on those, that increase the traffic safety (manoeuvre planning, forecasting), but underestimate the knowledge of prior knowledge of the risk factors that increases the probability of road accidents.

6. The respondents have not ranking at the forefront place of the ability to take correct action to the personal security and the safety of other road users, although in the purpose of threestage model of training of "responsible" drivers, this skill is a separate self. It is necessary in developing courses for proactive driving to pay particular attention to the influence of the culture and values of the individual, internal motives and their influence on the choice of behaviour model in driving.

\section{REFERENCES}

[1] Key competencies for a more competitive workforce in Bulgaria. Transfer of a complex innovative learning methodology from the Czech Republic, Handbook of the competence "Proactive Approach" http://competencies.nbschool.eu/node/25.

[2] Bateman Th. S., Michael J. Cr. Proactive behavior: meaning, impact, recommendations, Business Horizons, May/Jun99, Vol. 42 Issue 3, p63, 8p, 1 bw.

[3] Motivation to act, Journal of Business \& Economics Research - January, 2011 Volume 9, Number 1.

[4] Parker Sh. K., What is Proactivity, https://sites.google.com/site/profsharonparker/proactivity-research/what-is-proactivity.

[5] Pro-Active Driver Training - Light Vehicle, http://barbarogroup.com.au/wpcontent/uploads/2013/08/6-Steps-Brochure.pdf.

[6] Rusetski Al., Getting proactive: cultural and procedural drivers of managerial.

[7] The 7 Habits of highly effective people - Texas Tech University, https://www.depts.ttu.edu/upwardbound/books/the-7-habits-ofhighly-effective-people.pdf.

[8] Washington S., Cole R. J., Herbel S. B., European advanced driver training programs: Reasons for http://www.sciencedirect.com/science/article/pii/S0386111211000033. 